\title{
Discurso religioso e tradução: uma análise crítica da tradução de termos relativos ao sacerdócio $^{1}$
}

\author{
Religious Discourse and Translation: a Critical \\ Analysis of the Translation of Priesthood- \\ Related Terms
}

Benedito Gomes Bezerra*

Universidade de Pernambuco

Pernambuco - Ceará / Brasil

\begin{abstract}
RESUMO: Na ótica dos Estudos Críticos do Discurso (VAN DIJK, 2008), as relações de poder e abuso do poder, as diferentes formas de dominação sofridas por pessoas ou grupos sociais, são usualmente mediadas pela linguagem. Diante disso, o objetivo deste trabalho é examinar como, no domínio discursivo religioso, os tradutores da Bíblia (particularmente do Novo Testamento) evidenciam posições ideologicamente marcadas ao optarem por determinadas traduções do original grego para termos relacionados com a função sacerdotal, com implicaçōes para a legitimação discursiva de relações desiguais entre pares como clérigo-leigo e homem-mulher. Para o estudo, foram selecionadas três passagens do Novo Testamento, em que serão examinadas especialmente as

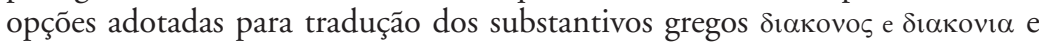

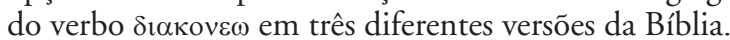

PALAVRAS-CHAVE: discurso; tradução; Novo Testamento; sacerdócio.

\begin{abstract}
In light of Critical Discourse Studies (van Dijk, 2008), power relations, abuse of power, and different forms of domination suffered by individuals or social groups are usually mediated by language. Thus, the objective of this study is to examine how translators of the Bible (particularly in the New Testament) show ideologically marked positions by choosing certain translations of the original Greek for priesthood-related terms, with implications for the discursive legitimation of unequal relations between such pairs as laity and clergy, and between men and women. For the study, we selected three passages of the
\end{abstract}

\footnotetext{
*beneditobezerra@gmail.com

${ }^{1}$ Uma versão anterior deste trabalho foi apresentada na XXIV Jornada Nacional do Grupo de Estudos Linguísticos do Nordeste (GELNE), realizada em Natal/RN, de 4 a 7 de setembro de 2012 .
} 
New Testament, in which we examine the options chosen for the translation of the Greek nouns diakonoV and diakonia, and the verb diakonew in three different Bible versions.

KEYWORDS: discourse; translation; New Testament; priesthood.

\section{Introdução}

Conforme evidenciam os Estudos Críticos do Discurso (VAN DIJK, 2008), as relações de poder e abuso do poder, as diferentes formas de dominação sofridas por pessoas ou grupos sociais, bem como as variadas formas de resistência e mudança dessas relações (FAIRCLOUGH, 2001) são usualmente mediadas pela linguagem. No domínio discursivo religioso, as relações entre os atores sociais têm a Bíblia (Antigo e Novo Testamento), livro sagrado do Cristianismo, como importante referencial normativo ${ }^{2}$ para as diversas práticas sociais, incluindo as relações de gênero e o acesso (ou a negação desse acesso) a funçōes e posiçōes sacerdotais. As relaçōes de poder que se estabelecem no referido domínio discursivo frequentemente são legitimadas por formas específicas de leitura da Bíblia, as quais, segundo a hipótese que orientou este trabalho, são forjadas de modo especial já a partir da tradução do texto bíblico das línguas originais para línguas de destino como a língua portuguesa.

A tradução da Bíblia apresenta-se hoje como uma questão relevante a ser discutida, uma vez que se tornou comum e acessível a qualquer leitor o manuseio de diferentes versóes do texto bíblico, o que levanta a pergunta pelas motivações discursivas e ideológicas que levam os comitês tradutores a adotarem certas leituras (opções de tradução, neste caso) em detrimento de outras. Hoje, os leitores em geral e os fiéis ligados tanto às igrejas evangélicas como à igreja católica, em particular, dispõem de um considerável leque de traduções da Bíblia, diferenciadas entre si por critérios como a linguagem mais ou menos contemporânea, a ausência ou a presença de notas explicativas bem como a natureza e o público visado por essas notas.

Um critério especialmente inovador em algumas traduções contemporâneas é a maior ou menor sensibilidade à questão do gênero. Não se trata apenas de se indagar o que diz o texto antigo em suas línguas originais, mas como esse dizer é recebido, compreendido e transmitido para os leitores

\footnotetext{
${ }^{2}$ Conforme destacado em Bezerra (2011), pesquisas apontam a Bíblia como o "gênero" mais lido por homens e mulheres no Brasil, o que evidencia a relevância dessa literatura como objeto de investigação de um ponto de vista crítico.
} 
através das traduções. Parto da premissa, neste caso, de que não existe algo como traduçôes objetivas e consequentemente inquestionáveis como se fossem as únicas possíveis. Toda tradução é presumivelmente informada pelos valores ideológicos que orientam os tradutores como membros de grupos sociais de prestígio. De acordo com Campos (2009, p.58), "o produto da atividade tradutória é resultado de processos de transformação, os quais são delineados por questôes de ordem social, histórica, política, ideológica, mas também particular, sendo a intervenção do tradutor algo inevitável" ${ }^{3}$

Em vista disso, meu objetivo neste trabalho é examinar como os tradutores da Bíblia, particularmente do Novo Testamento (NT), evidenciam posições ideologicamente marcadas ao optarem por determinadas traduçôes do original grego para termos relacionados com a função sacerdotal, com implicações para a legitimação discursiva de relações desiguais entre pares como clérigo-leigo e homem-mulher. Adicionalmente, interessa investigar como essas posições se refletem na tradução de passagens bíblicas em que os referidos pares se entrecruzam. Por exemplo, como os tradutores em geral tratam, no NT, um termo grego costumeiramente relacionado com as funções clericais se ele se referir, na passagem em questão, a uma mulher e não a um homem?

Para responder, ilustrativamente, a essas questões, selecionei três passagens bíblicas do NT, a saber, Rm 16.1, 1 Co 3.5 e At 6.2-4, ${ }^{4}$ nas quais serão examinadas, à luz do texto original em grego, as opções adotadas para

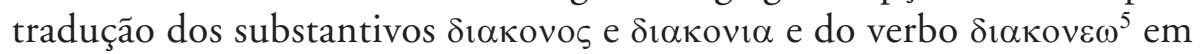
três diferentes versões da Bíblia em língua portuguesa, as quais também adotam diferentes critérios de tradução e assumem diferentes concepçôes sobre qual deveria ser a linguagem bíblica adequada em termos de registro. Trata-se, especificamente, das versões intituladas Almeida Revista e Corrigida (1995), Nova Versão Internacional (2001) e Nova Tradução na Linguagem de Hoje (2000).

Para a fundamentação teórica do estudo, adotarei, além dos aportes da

\footnotetext{
${ }^{3}$ A propósito disso, ver também Carmo (2011).

${ }^{4}$ Seguindo-se convenções comumente adotadas para referência ao texto bíblico, trata-se, respectivamente, dos trechos encontrados na Epístola aos Romanos, capítulo 16, versículo 1; Primeira Epístola aos Coríntios, capítulo 3, versículo 5; e Atos dos Apóstolos, capítulo 6, versículos 2-4.

5 Para facilitar a inserção do alfabeto grego no texto, não utilizarei o sistema de acentuação gráfica e as marcas de aspiração ("espíritos"), que por sinal ainda não existiam quando o NT foi escrito.
} 
Análise Crítica do Discurso (ACD), ${ }^{6}$ contribuições do campo da tradução bíblica e da exegese histórico-crítica do Novo Testamento numa perspectiva interdisciplinar, como requer a natureza da pesquisa proposta.

A fim de alcançar os seus objetivos, o artigo se organizará da seguinte maneira: primeiramente, indico as opções teórico-metodológicas que nortearão o trabalho no campo da Análise Crítica do Discurso. Em seguida, apresento algumas questôes pertinentes sobre a tradução da Bíblia, como os critérios de tradução e as peculiaridades de cada versão selecionada para estudo. Numa terceira etapa, faço uma breve discussão dos gêneros epístola e relato histórico no Novo Testamento, considerando suas implicações para a análise do discurso conforme ressignificado pelas traduçôes. Por último, apresento a análise das passagens bíblicas selecionadas para esta pesquisa. Concluo o trabalho com algumas considerações sobre o estudo realizado.

\section{Análise Crítica do Discurso: conceitos e categorias pertinentes}

Para os propósitos deste trabalho, apesar de utilizar o termo Análise Crítica do Discurso, já muito bem estabelecido no Brasil, identifico-me com o posicionamento de Teun van Dijk quando propõe a expressão alternativa Estudos Críticos do Discurso (ECD), considerando que estes não se referem a uma modalidade específica ou método peculiar de análise do discurso. Conforme o autor, não existe tal método, pois os ECD "usam qualquer método que seja relevante para os objetivos dos seus projetos de pesquisa" (VAN DIJK, 2008, p.10), e esses métodos também podem ser utilizados por outras modalidades de estudo do discurso. A Análise Crítica do Discurso em si não pode ser tratada como um método, mas como uma perspectiva que se utiliza de diversas metodologias e diversos aportes teóricos a fim de dar conta de seus interesses de pesquisa.

Operar em um campo interdisciplinar como a ACD implica, entre outras coisas, não se vincular dogmaticamente à perspectiva particular de qualquer um de seus autores mais destacados. Antes, consiste em optar por uma perspectiva "mestiça" (MOITA LOPES, 2006) já no âmbito interno da $\mathrm{ACD}$, se quisermos que essa mesma perspectiva guarde alguma coerência no diálogo com os estudos da linguagem em geral, bem como com outras disciplinas fora do campo da linguística.

\footnotetext{
${ }^{6}$ Ou Análise do Discurso Crítica, como preferem Ramalho e Resende (2006), entre outros.
} 
Assim, considero de extrema relevância para este estudo a perspectiva de uma "análise do discurso textualmente orientada" na linha proposta por Fairclough ([1992] 2001, 2003), para quem as diversas abordagens de análise do discurso podem ser classificadas, de modo geral, em "abordagens que incluem uma detalhada análise textual" e abordagens que não o fazem (FAIRCLOUGH, 2003, p.2). Nessa perspectiva, portanto, embora não se trate de reduzir a análise do discurso à análise de textos, compreendemos com o autor que "é impossível uma compreensão real dos efeitos sociais do discurso sem um olhar atento para o que acontece quando as pessoas falam ou escrevem" (p.3). O olhar para aspectos pontuais do texto permitirá a atenção a categorias importantes para este estudo, como é o caso das premissas e da representação de atores sociais conforme propostas por Fairclough (2003) e também discutidas por Ramalho e Resende (2011).

No caso específico deste estudo, meu argumento é que, quando os tradutores realizam seu trabalho, vale dizer, quando retextualizam (MARCUSCHI, 2001) o livro sagrado cristão, vertendo-o da língua original para a língua portuguesa, não estão apenas reproduzindo um texto, mas (re) produzindo discursos plenos de valores ideológicos e capazes de moldar, para o bem ou para o mal, o pensamento de expressivos contingentes de leitores. Assim, a análise crítica da atividade dos tradutores da Bíblia deverá ser simultaneamente uma "análise interdiscursiva", ou seja, deve enxergar os textos a partir dos diferentes discursos, gêneros e estilos de que lançam mão e que articulam conjuntamente (FAIRCLOUGH, 2003, p.3). Desta forma, analisar as opções de tradução dos itens linguísticos selecionados e indicados anteriormente, dentro das passagens bíblicas também indicadas, contemplando distintos gêneros textuais, ${ }^{7}$ é uma forma de acessar as práticas discursivas do domínio religioso com seus valores ideológicos ligados à questão do gênero e do acesso de homens e mulheres às funções sacerdotais.

Adicionalmente, considerando que o interesse principal da ACD é estudar "o modo como o abuso de poder, a dominação e a desigualdade são representados, reproduzidos e combatidos por textos orais e escritos no contexto social e político" (VAN DIJK, 2008, p.113), argumento ainda que a ação de traduzir pode ser vista, no quadro da ACD, como uma forma eficaz de "poder como controle" de grupos ou instituiçōes sobre "os atos e

\footnotetext{
${ }^{7}$ Nesse sentido, este trabalho tangencialmente se relaciona com a proposta de uma Análise Crítica de Gêneros conforme defendida por Bhatia (2007).
} 
as mentes ${ }^{8}$ dos (membros de) outros grupos" (p.117). De acordo com van Dijk (2008), para que esse controle aconteça, é necessário haver uma base de poder que permita o acesso privilegiado a recursos sociais escassos, que resulta em três formas diferentes de poder: o poder coercitivo dos militares e dos homens violentos, baseado na força; o poder econômico dos ricos, baseado no dinheiro; e o poder simbólico de pais, professores e jornalistas, baseado na autoridade, no conhecimento e na informação. O poder, continua van Dijk (2008, p.118), nem sempre é exercido de forma claramente abusiva, mas pode estar incorporado às açóes "normais" da vida cotidiana, deixando consequentemente de ser visto como um problema.

O poder exercido pelos tradutores, que em última análise definem a forma exata do texto sagrado a ser lido pelas pessoas em geral, se dá, assim, como poder simbólico dissimulado nas práticas cotidianas de leitura e interpretação das passagens bíblicas. Apesar de seu impacto sobre as mentes dos seus leitores, essa realidade dificilmente será percebida como abusiva ou problemática. No entanto, trata-se de um problema considerável, se levarmos em conta, como ressaltam Gabel e Wheeler (1993, p.205), que a maioria das pessoas somente leu a Bíblia em tradução e, consequentemente, de alguma forma "nem a metade de um por cento" leu as palavras reais da Bíblia, mas sim o resultado do trabalho dos tradutores com todas as suas implicações. Quanto a estes, seu poder consiste no acesso privilegiado ao texto nas línguas originais, que lhes confere a autoridade de decidir o que o livro sagrado "realmente" quer dizer, sendo impossível, para uma ampla maioria dos leitores, contestar suas decisões. Segundo van Dijk (2008, p.119), "em muitas situaçôes, as pessoas comuns são alvos passivos, em maior ou menor grau, de seus chefes, professores ou autoridades [...] os quais podem simplesmente dizer-lhes em que devem (ou não) acreditar ou o que podem (ou não) fazer".

Dessa forma, além do controle do discurso, o controle da mente é outra forma poderosa de reprodução da dominação pelo abuso de poder, pois, ainda segundo van Dijk (2008, p.121), "os receptores tendem a aceitar crenças, conhecimento e opiniōes [...] através do discurso produzido por aqueles que são considerados fontes autorizadas, confiáveis ou críveis, tais como acadêmicos, peritos, profissionais", como é o caso dos tradutores

\footnotetext{
${ }^{8}$ Notar aqui a contribuição peculiar de Teun van Dijk para a ACD com sua tríplice perspectiva articulando discurso, sociedade e cognição.
} 
da Bíblia. Entre outros aspectos do controle da mente, van Dijk (2008) destaca: em algumas situações (como na leitura da Bíblia, acrescente-se), os participantes são constrangidos a se tornar meros receptores do discurso, no sentido de que não podem eles mesmos acessar o texto original, tendo apenas que aceitar o trabalho dos especialistas. Segue-se, consequentemente, que os receptores do trabalho dos tradutores não possuem "o conhecimento e as crenças necessárias para questionar o discurso ou a informação a que são expostos" (p.122). Verifica-se, assim, que a atividade de tradução do texto bíblico se apresenta como uma ocasião fértil para a disseminação e sedimentação dos valores ideológicos de interesse dos tradutores (suas premissas), sejam estes conscientes ou não desse fato.

\section{A Bíblia em tradução: "fidelidade" ao texto antigo ou ao leitor contemporâneo? ${ }^{9}$}

Como ressaltei acima, a quase totalidade dos leitores da Bíblia necessita, para conhecer as Escrituras judaico-cristãs, confiar na precisão e capacidade de transmissão das traduções. Por isso mesmo, os tradutores da bíblia protestante inglesa King James Version (1611) tinham em alta conta o seu próprio trabalho, considerando que "é a tradução que abre a janela, para deixar a luz entrar; que quebra a casca, a fim de podermos comer a polpa; que abre a cortina, a fim de podermos olhar o lugar mais sagrado; que remove a tampa do poço, a fim de podermos tirar água" - conforme afirmam no prefácio em que se dirigem ao leitor (apud MILTON, 1998, p.2). Estavam, portanto, muito longe de concordar com o trocadilho italiano para quem o tradutor é um traidor (traduttore-traditore). Ou, nos termos da ACD, que a atividade do tradutor comporta um elevado grau de autoridade e poder de controlar o discurso e a mente do seu público.

Um eventual juízo sobre a qualidade ou a "fidelidade" das traduções da Bíblia varia em função dos diferentes propósitos que movem o empreendimento. Do ponto de vista literário, as melhores traduções da Bíblia são aquelas que reproduzem as formas dos originais, e não sua "mensagem". Conforme Milton (1998, p.167), o poeta, linguista e crítico literário francês Henri Meschonnic (1973, p.308) acreditava que "a tradução facilitada, aquela que tenta parecer como se tivesse sido escrita na língua-

\footnotetext{
9 Neste tópico, retomo parcialmente considerações feitas em trabalho anterior (BEZERRA, 2011).
} 
alvo, é uma maneira de introduzir uma ideologia e um sistema de valores estranhos na cultura-alvo". Contudo, para Eugene Nida (1964), especialista em tradução da Bíblia, o mérito de uma tradução está em expressar com naturalidade o sentido do texto bíblico na língua-alvo. Nas palavras de Nida e Taber (1974, p.12), "a tradução consiste em reproduzir na língua receptora o mais próximo equivalente natural da mensagem da língua-fonte, primeiro em termos de significação e segundo em termos de estilo".

A teoria da tradução aplicada à Bíblia, especialmente no contexto protestante, em geral se orienta pelos princípios da equivalência formal ou da equivalência dinâmica, também conhecida como equivalência funcional, entre as línguas de origem (hebraico e aramaico para o Antigo Testamento e grego para o Novo Testamento) e a língua de destino (português ou outra). As noções de equivalência formal, por um lado, e de equivalência dinâmica ou funcional, por outro, foram propostas por Nida (1964). No enfoque desse autor, a equivalência formal corresponde, no quadro mais amplo das teorias da tradução, às "teorias tradicionais" concentradas no texto-fonte, enquanto a equivalência funcional/dinâmica se concentra no texto-alvo. ${ }^{10}$ Visto que nenhuma tradução aplica esses princípios de maneira absoluta, sob pena de comprometer a qualidade do trabalho, o que verificamos é uma questão de predominância de um ou de outro princípio em cada tradução. As três versões selecionadas para este estudo estão posicionadas de forma peculiar em relação aos polos da equivalência formal $\mathrm{x}$ funcional, tendo sido precisamente este um dos critérios para sua inclusão na pesquisa.

O princípio da equivalência formal predomina nas versões mais tradicionais, que parcialmente em virtude disso também se caracterizam por uma linguagem mais arcaica, formal e erudita. Versões orientadas por esse princípio, como é o caso das diferentes edições da tradução em português de João Ferreira de Almeida, procuram representar a língua original palavra por palavra na língua de destino. São traduções bastante literais e que refletem a língua original de maneira bem próxima, inclusive do ponto de vista do estilo e da sintaxe. A versão conhecida como Almeida Revista e Corrigida (1995), cuja primeira edição remonta a 1898, é o exemplo mais conservador de tradução literal realizada segundo o princípio da equivalência formal. Segundo afirma em seu site a Sociedade Bíblica do Brasil (www.sbb.org.

${ }^{10}$ Para uma abordagem mais ampla a uma tipologia ou a princípios de tradução, ver Olmi (2002), Gentzler (2009) e Oustinoff (2011). 
br), principal casa publicadora dessa versão bíblica, "a tradução de Almeida é a preferida de mais de $60 \%$ dos leitores evangélicos no País", apesar de apresentar uma linguagem que possivelmente não será compreendida por muitos leitores. Quanto aos princípios de tradução, a SBB informa:

Os princípios que regem a tradução de Almeida são os da equivalência formal, que procura seguir a ordem das palavras que pertencem à mesma categoria gramatical do original. A linguagem utilizada é clássica e erudita. Em outras palavras, Almeida procurou reproduzir no texto traduzido os aspectos formais do texto bíblico em suas línguas originais hebraico, aramaico e grego - tanto no que se refere ao vocabulário quanto à estrutura e aos demais aspectos gramaticais.

Já o princípio da equivalência dinâmica predomina em versões mais contemporâneas, em geral preocupadas com o uso de uma linguagem mais atualizada, em parte mais coloquial e mais fácil de ser entendida pelos leitores de hoje. Traduções orientadas por esse princípio pretendem representar com maior exatidão o sentido e não a forma do texto original na língua de destino. Acreditam que só assim o texto bíblico produzirá no leitor de hoje o mesmo impacto que causou no leitor do passado. O melhor exemplo de versão orientada por esse princípio em português é a Nova Tradução na Linguagem de Hoje (2000), que representa uma revisão da Tradução na Linguagem de Hoje de 1988. Essa versão é descrita pela Sociedade Bíblica do Brasil, também responsável por sua edição, como

Clara, exata e natural. Assim pode ser definida a Nova Tradução na Linguagem de Hoje (NTLH). Lançada no ano 2000, essa é a tradução da Bíblia que mais tem crescido na preferência dos cristãos. Sem perder a fidelidade aos textos originais - hebraico, aramaico e grego -, adota uma estrutura gramatical e linguagem mais próximas da utilizada pelo brasileiro.

Conforme os editores, enquanto a tradução de Almeida tem 8,38 mil palavras diferentes, a NTLH tem apenas 4,39 mil, "o que a aproxima muito mais do vocabulário dominado pelo brasileiro de cultura média”. Essa preocupação com um vocabulário simples é também uma característica da tradução por equivalência funcional ou dinâmica.

Representando um meio termo entre as versões Almeida Revista e Corrigida e a Nova Tradução na Linguagem de Hoje, do ponto de vista dos princípios de tradução, a Nova Versão Internacional (2001) apresenta uma tendência nem sempre consistente em direção ao princípio de equivalência 
dinâmica. A Sociedade Bíblica Internacional, responsável pela tradução, informa em seu site (www.biblicabrasil.org.br) que "os tradutores não se prenderam a um único método de tradução". Ainda de acordo com os editores a tradução "acompanha a variedade de gêneros, estilos e níveis estilísticos presentes nos originais bíblicos. Traz formas de apresentação que facilitam a leitura, a apreensão da natureza dos textos e sua compreensão". Apesar de não afirmar claramente a opção por um ou outro método de tradução, e apesar de ser bem mais "fiel" aos originais (isto é, mais literal) do que a NTLH, tudo indica que a Nova Versão Internacional é a versão bíblica mais atacada e questionada por supostos problemas doutrinários gerados pela tradução, como uma consulta a um motor de busca na Internet rapidamente demonstrará. ${ }^{11}$

Deve ficar claro, mais uma vez, que as versões bíblicas em geral se caracterizam como mais formais e menos dinâmicas, e vice-versa, num continuum, não havendo versões cem por cento consistentes na aplicação da equivalência formal ou da equivalência dinâmica. Com respeito ao uso de uma linguagem sensível à questão do gênero, não são, como se poderia supor, apenas as traduções de equivalência dinâmica que a utilizam, porque muitas vezes essa linguagem é exigida para que uma boa representação do texto seja feita na língua de destino. Não serão poucos os especialistas que concordarão em que "toda tradução emprega linguagem inclusiva de gênero até certo ponto" (MINTON, 2003, p.142), até aquelas em que os seus usuários e defensores são contrários a essa linguagem.

O debate sobre usar ou não usar procedimentos de tradução sensíveis à questão do gênero parece muito mais acirrado no plano internacional do que no contexto brasileiro. Nesse debate, podemos delinear pelo menos três posturas diferentes sobre o assunto: primeiramente, a postura dos grupos fundamentalistas que escrevem raivosos libelos contra essa linguagem que segundo eles "distorce" a Bíblia, e contra as versóes bíblicas que a representam; no outro extremo, a postura de grupos como as feministas que propõem revisões radicais da linguagem bíblica do ponto de vista do

${ }^{11}$ A título de ilustração, uma pesquisa no Google sobre "críticas à Nova Versão Internacional" resulta em sites que se dedicam a "expor os erros da NVI", tais como Sola scriptura TT (http://solascriptura-tt.org/Bibliologia-PreservacaoTT/Expondo ErrosNVI-Jun2000-Emidio.htm); ou outros que, de forma mais virulenta, classificam a versão como "maldita", caso do site Igreja livre (http://igrejalivreemmovimento. blogspot.com.br/2010/08/nova-versao-internacional-nvi-da-biblia.html). 
gênero (por exemplo, traduzir "Deus de Abraão" como "Deus de Abraão, Sara e Hagar"); finalmente, uma posição moderada, representada por evangélicos que, mesmo aceitando doutrinas conservadoras como a chamada "inerrância da Bíblia", também defendem que a tradução em linguagem inclusiva de gênero é desejável, especialmente "quando o uso de tal linguagem representa com exatidão o sentido do texto original" (STRAUSS, 2003, p.5).

A questão do gênero, como será ressaltado na análise apresentada neste trabalho, se torna ainda mais crucial quando relacionada ao acesso das mulheres às funções sacerdotais, tradicionalmente atribuídas a homens e exercidas quase exclusivamente por eles. Trata-se de discutir em que medida essa limitação do acesso feminino às funções sacerdotais é naturalizada e reforçada pela atividade de tradução do texto bíblico.

\section{Os gêneros epístola e relato histórico no Novo Testamento}

Dos vinte e sete escritos que compõem o Novo Testamento, as diferentes versões da Bíblia em português (bem como noutras línguas) tradicionalmente identificam vinte e um como sendo epístolas ou cartas. ${ }^{12}$ Dos seis documentos restantes, quatro são classificados como evangelhos, um como relato histórico e outro como apocalipse. As epístolas, portanto, ocuparam lugar central na organização da vida das primeiras comunidades cristãs, razão por que foram acolhidas no cânon em tão grande número, enquanto outros gêneros foram rejeitados, como foi o caso de muitos evangelhos e apocalipses que foram descartados como "apócrifos".

As cartas representam os escritos mais antigos do Novo Testamento, pois, ao contrário do que parece sugerir a ordem dos documentos no cânon neotestamentário, elas começaram a ser produzidas décadas antes dos evangelhos. Entre as epístolas do Novo Testamento, destaca-se o chamado corpus paulinum, composto por treze cartas atribuídas pela antiga tradição cristã ao apóstolo Paulo, "o criador da carta apostólica" (MORESCHINI; NORELLI, 1996), embora a pesquisa exegética contemporânea, especialmente quando pautada no método histórico-crítico,

\footnotetext{
${ }^{12}$ Não levamos em conta, aqui, a antiga distinção proposta por Adolf Deissman (apud Moreschini e Norelli, 1996) entre cartas (comunicação privada) e epístolas (tratados públicos na forma de carta).
} 
questione a autoria paulina de pelo menos a metade desse corpus. Entretanto, as cartas selecionadas para este estudo, quais sejam, Romanos e 1 Coríntios, integram a parte inquestionável do conjunto, sendo consideradas pela crítica em geral como cartas legitimamente paulinas e podendo ser localizadas com relativa clareza no quadro da atividade histórica do apóstolo (ver, por exemplo, Kümmel, 1982).

As antigas cartas cristãs eram consideradas escritos ocasionais, uma vez que procuravam resolver os problemas que iam surgindo nas diversas comunidades originalmente fundadas por Paulo. Nas palavras de Moreschini e Norelli (1996, p. 32), as cartas do NT "não foram escritas para os pósteros, mas para servirem às exigências do momento”. De acordo com Kümmel (1982, p. 318), "as epístolas paulinas que chegaram até nós são epístolas do Apóstolo em caráter oficial; servem para levar adiante sua atividade missionária, à distância”. Por isso mesmo, por assumirem propósitos comunicativos peculiares, não se limitam a reproduzir as formas genéricas comuns ao ambiente em que surgiram:

A força motriz para a formação independente da forma epistolar num meio de autocomunicação literária da cristandade foi a real necessidade da missão [...] A forma das epístolas mais comuns contidas no NT não está diretamente relacionada com a epístola helenística (cf. Epicuro, Sêneca) ou com a epístola judeu-helenística (por ex., a Carta de Aristeias) (KÜMMEL, 1982, p. 319).

Os problemas enfocados pelas epístolas podiam ser de caráter disciplinar, relacional ou ainda doutrinário, o que fez com que as cartas se tornassem o repositório mais primitivo da teologia cristã. Nesse sentido, a Carta aos Romanos ocupa um lugar peculiar no corpus paulinum por duas razōes: (1) a comunidade dos cristãos em Roma não havia sido fundada por Paulo; e (2) o apóstolo, desejando visitar e ser recebido por aquela comunidade, escreve-lhe uma longa epístola em que, entre outras coisas, desenvolve sistematicamente a sua compreensão da doutrina cristã, mais do que em qualquer outra de suas cartas. Já a Primeira Carta aos Coríntios figura entre as grandes epístolas relacionadas sem sombra de dúvidas com a atividade missionária direta de Paulo.

Por sua vez, o relato histórico ${ }^{13}$ é representado no NT pelo livro de Atos

${ }^{13}$ Há uma boa discussão, entre os especialistas em NT, sobre em que sentido pode-se 
dos Apóstolos, tradicionalmente atribuído a Lucas, um dos colaboradores de Paulo. Os pesquisadores da área acreditam, com base nos prólogos de ambos os livros, que Atos é o segundo volume de uma obra que começa com o Evangelho de Lucas. Assim, conforme Kümmel, "os Atos não são uma obra literária à parte” (1982, p.194). O livro se propõe a dar seguimento a uma narrativa "ordenada" dos primórdios da igreja cristã, embora se concentre preferencialmente nas ações de Pedro (até o capítulo 12) e de Paulo (do capítulo 13 ao 28). Continua, dessa forma, a narrativa que começara com o anúncio do nascimento de João Batista e de Jesus, no Evangelho de Lucas, e concluíra com o relato da ascensão de Jesus após a ressurreição. Ambos os volumes são dedicados a alguém chamado Teófilo, que pode ou não tratar-se de um indivíduo real, uma vez que o nome significa simplesmente "amigo de Deus".

\section{Análise da tradução de $\delta \imath \alpha \kappa o v o \zeta, \delta ı \alpha \kappa o v ı \alpha$ e $\delta \imath \alpha \kappa o v \varepsilon \omega$ em Rm 16.1, 1 Co 3.5 e At 6.2-4}

\subsection{Romanos 16.1}

O capítulo 16, último da Carta aos Romanos, é composto principalmente por saudações diversas do apóstolo Paulo a pessoas conhecidas em Roma. Antes dessas saudações, entretanto, o apóstolo abre o capítulo ${ }^{14}$ com a recomendação de uma mulher chamada Febe, para que os cristãos romanos a recebessem de forma "digna dos santos", como Paulo acreditava que ela merecia, como colaboradora que era do seu trabalho apostólico e do trabalho da igreja em Cencreia. Na maneira altamente elogiosa como Paulo a recomenda, merece atenção o termo que o apóstolo utiliza para descrevê-la, conforme destacado abaixo.

dizer que Atos é "história”. Com certeza, não no sentido da historiografia moderna, mas nos moldes da história antiga, o livro procura apresentar um relato dos "atos" de destaque praticados pelos principais apóstolos ao longo do segundo e terceiro quartos do século I - a propósito disso, ver Moreschini e Norelli (1996) e Kümmel (1982), entre outros.

${ }^{14}$ É verdade que, como a divisão em capítulos é bastante posterior à redação da epístola, "abrir" o capítulo não deixa de ser apenas uma maneira de falar, levando em conta a divisão atual da carta. 
QUADRO 1

Três versões de $\mathrm{Rm} 16.1$

\begin{tabular}{|c|c|}
\hline Versão bíblica & Romanos 16.1 \\
\hline Texto original (grego) + tradução literal $^{15}$ & 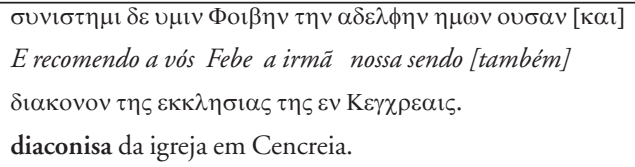 \\
\hline Almeida Revista e Corrigida (ARC) & $\begin{array}{l}\text { Recomendo-vos, pois, Febe, nossa irmã, } \\
\text { a qual serve na igreja que está em Cencreia. }\end{array}$ \\
\hline Nova Versão Internacional (NVI) & $\begin{array}{l}\text { Recomendo-lhes nossa irmã Febe, } \\
\text { serva da igreja em Cencreia. }\end{array}$ \\
\hline $\begin{array}{l}\text { Nova Tradução na Linguagem de Hoje } \\
\text { (NTLH) }\end{array}$ & $\begin{array}{l}\text { Eu recomendo a vocês a nossa irmã Febe, que é } \\
\text { diaconisa da igreja de Cencreia. }\end{array}$ \\
\hline
\end{tabular}

Fonte: Elaborado pelo autor.

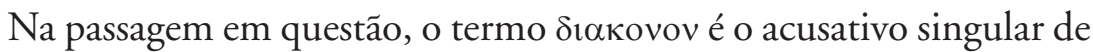

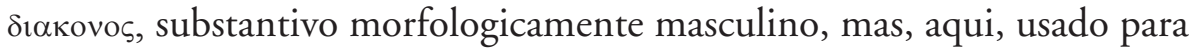
o gênero feminino. No NT, esse termo é utilizado em diversas passagens com os sentidos possíveis de "servo", "ministro" ou "diácono", este último na verdade o simples empréstimo do termo grego, transliterado no alfabeto romano (cf. GINGRICH; DANKER, 1993; THE ANALYTICAL GREEK LEXICON, s.d.).

No contexto do cristianismo primitivo, na mentalidade dos tradutores da Bíblia, qualquer pessoa poderia ser referida como "serva", independentemente das funções que exercesse ou deixasse de exercer na comunidade. $\mathrm{O}$ termo ressalta o status dos cristãos em relação àquele que

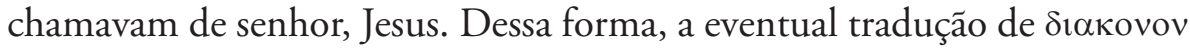
como "servo" pode ser uma representação ambígua dos atores sociais, pois o "servo" tanto poderia ser o líder da comunidade como um de seus membros menos destacados. Essa ambiguidade na representação dos atores sociais pode revelar premissas ideológicas sobre os papéis, por exemplo, de homens e mulheres em relação ao sacerdócio e a outras funções eclesiais.

Quanto ao termo "ministro", a linguagem dos tradutores o reserva para pessoas que exerciam funções hoje vistas como sacerdotais ou "ministeriais", isto

${ }^{15}$ A tradução literal provém do NT interlinear publicado pela Sociedade Bíblica do Brasil (2004). 
é, ligadas a alguma posição oficial na estrutura da igreja, embora essa estrutura a rigor não existisse como tal no cristianismo primitivo. Dessa forma, poucas pessoas são chamadas de ministros no Novo Testamento, e provavelmente isso só acontecerá com homens e não com mulheres, embora haja boas evidências de que as mulheres tenham exercido funções de destaque nas primeiras comunidades, até porque estas tinham os lares como sua principal base de funcionamento.

Finalmente, o termo "diácono" representa o empréstimo linguístico do

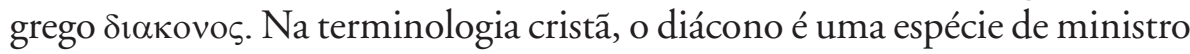
de status mais baixo do que o sacerdote em si, exercendo, consequentemente, funçôes auxiliares de "serviço" na comunidade cristã (ver a discussão de At 6.2-4, adiante). Ele não é um cristão "comum", mas também não é um "ministro".

Como podemos perceber, a ARC apresenta a tradução "a qual serve",

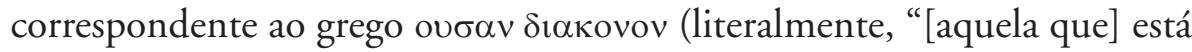
sendo serva/diaconisa/ministra"). A NVI, por sua vez, traduz o termo

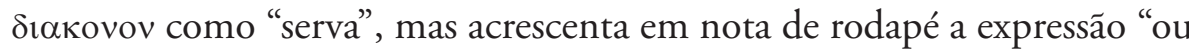
diaconisa", quer dizer, o comitê tradutor apresenta duas possibilidades, mas evidentemente dá preferência àquela que é incluída no corpo do texto. Do ponto de vista da $\mathrm{ACD}$, essa forma de representação de Febe coloca em evidência a premissa dos tradutores da ARC e da NVI de que, em se tratando de uma mulher, o sentido normal do texto grego deve ser de "serva", e não uma tradução de sentido mais clerical como "ministra" ou "diaconisa", embora a NVI admita a possibilidade deste último.

Quanto aos tradutores da NTLH, sua opção foi pela tradução como "diaconisa", que seria, como afirmei anteriormente, o meio termo entre "serva" e "ministra". Se, por um lado, essa tradução tem o mérito de atribuir à mulher uma função especial na comunidade cristã, por outro lado, não apresenta a possibilidade, linguisticamente evidente, de que essa função pudesse ser de natureza sacerdotal. Adicionalmente, note-se que a tradução "diaconisa" não se enquadra no propósito central anunciado da NTLH que é oferecer uma linguagem de fácil compreensão, mas sim revela certa abertura e sensibilidade para a questão do gênero, inclusive no que diz respeito a uma função tradicionalmente atribuída apenas a homens.

Vejamos agora como agem os tradutores diante da mesma palavra grega em um contexto que se refere apenas a homens, e estes ligados a funções de liderança no cristianismo do primeiro século. 


\subsection{Coríntios 3.5}

QUADRO 2

Três versões de 1 Co 3.5

\begin{tabular}{|c|c|}
\hline Versão bíblica & 1 Coríntios 3.5 \\
\hline Texto original (grego) + tradução literal & 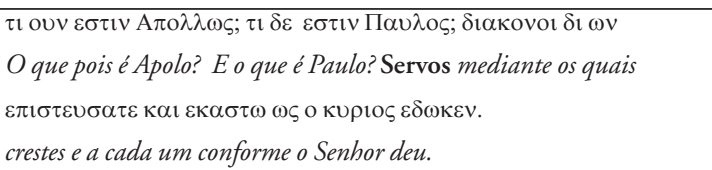 \\
\hline Almeida Revista e Corrigida (ARC) & $\begin{array}{l}\text { Pois quem é Paulo e quem é Apolo, senão ministros pelos quais } \\
\text { crestes, e conforme o que o Senhor deu a cada um? }\end{array}$ \\
\hline Nova Versão Internacional (NVI) & $\begin{array}{l}\text { Afinal de contas, quem é Apolo? Quem é Paulo? Apenas servos } \\
\text { por meio dos quais vocês vieram a crer, conforme o ministério que o } \\
\text { Senhor atribuiu a cada um. }\end{array}$ \\
\hline $\begin{array}{l}\text { Nova Tradução na Linguagem de Hoje } \\
\text { (NTLH) }\end{array}$ & $\begin{array}{l}\text { Afinal de contas, quem é Apolo? E quem é Paulo? Somos somente } \\
\text { servidores de Deus, e foi por meio de nós que vocês creram no } \\
\text { Senhor. Cada um de nós faz o trabalho que o Senhor lhe deu para } \\
\text { fazer. }\end{array}$ \\
\hline
\end{tabular}

Fonte:Elaborado pelo autor.

Nessa passagem, Paulo está combatendo tendências partidaristas da igreja situada na cidade grega de Corinto, pelas quais grupos tendiam a se formar em torno dos nomes de líderes influentes como Paulo e Apolo. Nesse

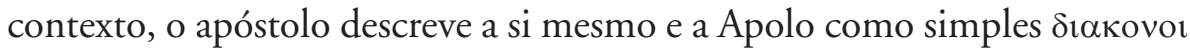
(nominativo plural de $\delta 1 \alpha \kappa o v o \varsigma$ ) através dos quais os cristãos coríntios conheceram a fé em Jesus Cristo.

Neste caso, percebe-se que a versão ARC traz a tradução mais formal e solene, qualificando Paulo e Apolo como "ministros", de modo bem diferente de como fizera em relação a Febe na passagem anterior (Rm 16.1). Em ambos os casos, o contexto indica que se trata de pessoas que desempenhavam papéis bastante especiais no âmbito das respectivas igrejas locais. No entanto, se a mulher Febe era, para os tradutores, uma "serva" da igreja, aqui os homens Paulo e Apolo são imediatamente representados como "ministros" a serviço do Senhor. Nota-se claramente como os atores sociais são representados de formas bastante diferentes, sendo um fator determinante para essa representação a questão do gênero: ao que parece, os tradutores assumem como evidente que mulheres são servas e homens são ministros.

Já na ótica dos tradutores das versões NVI e NTLH, não pareceu necessário ressaltar o status "ministerial" de Paulo e Apolo, uma vez que o contexto não deixa dúvidas de que se trata de homens executando a missão especial de levar pessoas à fé, de modo que se torna desnecessário representar 
os referidos personagens como "ministros". Assim, ambas as versōes traduzem

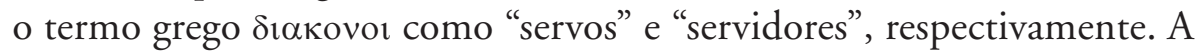
mensagem, neste caso, é: mesmo ministros inquestionáveis como Paulo e Apolo também são apenas servos quando executam a missão. A premissa parece ser, portanto, que ambos são ministros, mas na passagem em questão não seria necessário ressaltar esse fato.

Essa premissa, no entanto, é reforçada pelo acréscimo, por conta dos tradutores, de expressóes que não fazem parte do texto original. No caso da NVI, o comitê tradutor acrescenta a expressão "conforme o ministério". Considerando que essa palavra usualmente traduz o grego $\delta$ เ $\alpha$ kovı $\alpha$, da mesma

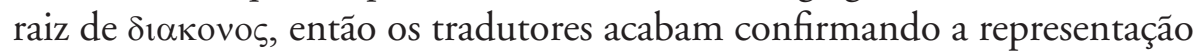
desses atores sociais como ministros ao designarem a atividade deles como "ministério". Os tradutores da NTLH, por sua vez, acrescentam ao texto a expressão "o trabalho", termo que também pressupõe a palavra $\delta 1 \alpha \kappa o v i \alpha$, embora esta não apareça no original. Positivo nessa versão é que o termo "trabalho" é bem mais neutro do ponto de vista ideológico, no contexto, do que "ministério". De acordo com a NTLH, portanto, Paulo e Apolo são "servidores" que executam o "trabalho" que o Senhor lhes "deu para fazer".

\subsection{Atos 6.2-4}

\section{QUADRO 3}

Três versōes de At 6.2-4

\begin{tabular}{|c|c|}
\hline Versão bíblica & Atos 6.2-4 \\
\hline $\begin{array}{l}\text { Texto original (grego) + tradução } \\
\text { literal }\end{array}$ & 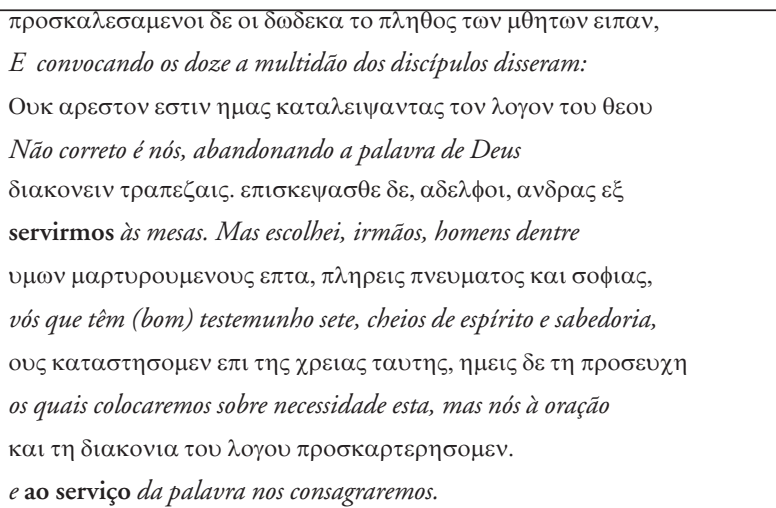 \\
\hline $\begin{array}{l}\text { Almeida Revista e Corrigida } \\
\text { (ARC) }\end{array}$ & $\begin{array}{l}\text { E os doze, convocando a multidão dos discípulos, disseram: Não é razoável } \\
\text { que nós deixemos a palavra de Deus e sirvamos às mesas. Escolhei, pois, } \\
\text { irmãos, dentre vós, sete varões de boa reputação, cheios do Espírito Santo } \\
\text { e de sabedoria, aos quais constituamos sobre este importante negócio. Mas } \\
\text { nós perseveraremos na oração e no ministério da palavra. }\end{array}$ \\
\hline
\end{tabular}




\begin{tabular}{|l|l|}
\hline $\begin{array}{l}\text { Nova Versão Internacional } \\
\text { (NVI) }\end{array}$ & $\begin{array}{l}\text { Por isso os Doze reuniram todos os discípulos e disseram: "Não é certo } \\
\text { negligenciarmos o ministério da palavra de Deus, a fim de servir às mesas. } \\
\text { Irmãos, escolham entre vocês sete homens de bom testemunho, cheios do } \\
\text { Espírito e de sabedoria. Passaremos a eles essa tarefa e nos dedicaremos à } \\
\text { oração e ao ministério da palavra". }\end{array}$ \\
\hline $\begin{array}{l}\text { Nova Tradução na Linguagem de } \\
\text { Hoje (NTLH) }\end{array}$ & $\begin{array}{l}\text { Então os doze apóstolos reuniram todo o grupo de seguidores e disseram: } \\
\text { Não está certo nós deixarmos de anunciar a palavra de Deus para tratarmos } \\
\text { de dinheiro. Por isso, irmãos, escolham entre vocês sete homens de } \\
\text { confiança, cheios do Espírito Santo e de sabedoria, e nós entregaremos esse } \\
\text { serviço a eles. Assim nós poderemos continuar usando todo o nosso tempo } \\
\text { na oração e no trabalho de anunciar a palavra de Deus. }\end{array}$ \\
\hline
\end{tabular}

Fonte: Elaborado pelo autor.

Nesse texto, encontramos pela primeira vez a forma $\delta 1 \alpha \kappa o v \varepsilon \imath v$,

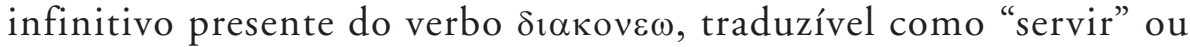

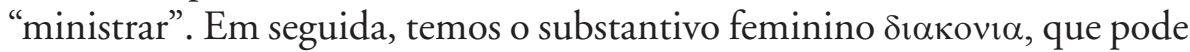
ser traduzido como "serviço" ou "ministério". Desnecessário ressaltar que a opção por uma ou outra tradução, no que diz respeito tanto ao verbo como ao substantivo, depende principalmente do juízo do tradutor sobre o status da atividade descrita, qual seja, se ela pode ser classificada como serviço simplesmente ou como algo mais "digno", um ministério. Vale dizer, nos termos propostos por Fairclough (2003), que a tradução depende da premissa dos tradutores sobre a atividade apresentada pelo texto. Vejamos as peculiaridades da tradução em cada versão sob análise.

As opções dos tradutores da ARC são claras: apesar de se tratar de um verbo e um substantivo da mesma raiz, o primeiro, por se referir à atividade aparentemente mais modesta de atender às necessidades materiais das viúvas helenistas, é traduzido simplesmente como servir ("Não é razoável que nós deixemos a palavra de Deus e sirvamos às mesas"). Nos termos de hoje, é o equivalente a afirmar que os projetos sociais das igrejas não podem ser descritos como ministérios, mas como simples "serviços". Já o substantivo, na passagem em questão, é entendido pelos tradutores da ARC como "ministério", uma vez que está ligado diretamente à "palavra", termo que subentende o complemento "do Evangelho". Ou seja, a dıккоvı em questão é o anúncio do Evangelho, que "só" pode ser classificado como ministério.

Esse tratamento desigual da atividade social da igreja em relação à atividade da pregação reflete-se atualmente na hegemonia do sacerdócio sobre os ministérios auxiliares, na terminologia protestante, ou as pastorais sociais, na terminologia católica. Apesar de não haver respaldo para isso no texto original, a tradução ajuda a construir e/ou manter a noção da 
superioridade do sacerdócio sobre as demais funções desempenhadas na igreja.

O comitê tradutor da versão NVI adota procedimentos muito semelhantes aos da ARC, também compreendendo a atividade social da igreja como "serviço" e o anúncio do Evangelho como "ministério", mas com um reforço mais ou menos sutil, já percebido no comentário de 1 Co 3.5: o acréscimo de palavras que não constam no texto original. Mais uma vez, a palavra "ministério" é acrescentada onde o grego não tem um termo correspondente. Dessa forma, a NVI traz "não é certo negligenciarmos o ministério da palavra de Deus", reforçando a ideia de que lidar com a palavra de Deus é exercer um ministério, especialmente em contraste com o complemento do enunciado que fala de "servir às mesas". A tradução autoriza o leitor a inferir que o ministério da palavra de Deus é mais importante do que o serviço às mesas, uma inferência que vai além do que o texto original parece sugerir: os apóstolos não se sentiam chamados para tratar de assuntos assistenciais, mas procuram com toda seriedade eleger pessoas bem preparadas, "cheios do Espírito e de sabedoria", para aquele ministério alternativo. Não se trata de decidir qual atividade é mais digna ou mais importante.

A NTLH, de modo bastante similar às versões anteriores, também reforça uma noção hierarquizante entre o ministério social e o ministério da palavra. No caso deste, os tradutores representam os apóstolos como anunciando a palavra, inclusive, à maneira da NVI, acrescentando a primeira ocorrência de "anunciar", que não tem respaldo no texto grego. Anunciar é termo técnico, no Novo Testamento, para pregar o Evangelho. A dignidade e o status elevado dessa atividade não são ameaçados nem mesmo pela tradução

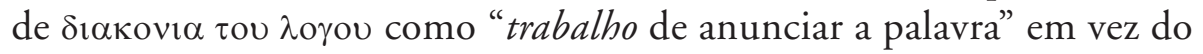
esperado "ministério". Quanto à $\delta 1 \alpha \kappa o v ı \alpha$ das mesas, esta é totalmente descaracterizada pela tradução "tratarmos de dinheiro", equivalente ao

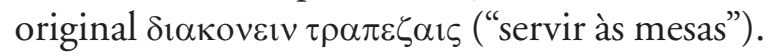

\section{Considerações finais}

Neste breve estudo, acredito ter ilustrado com relativa clareza, a partir dos itens lexicais selecionados e discutidos nas três passagens bíblicas examinadas, de que modo as premissas dos tradutores os levam a representar os atores sociais encontrados na Bíblia de certa maneira e não de outra, imprimindo no seu trabalho de tradução as marcas ideológicas e os valores 
de grupos hegemônicos, sejam eles os homens em relação às mulheres ou os ministros religiosos em relação aos leigos. Dados os (necessários) limites e escopo do trabalho, pesquisas posteriores poderão contribuir para uma compreensão mais ampla dessas questóes.

No que diz respeito à relação homem x mulher, e no que tange ao acesso a funções eclesiais, vimos, na análise de Rm 16.1, como a tradução

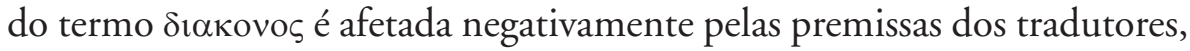
que os induzem a evitar traduçóes que representem a mulher como ocupando posições de destaque na hierarquia eclesiástica. Pelas premissas dos tradutores, contra todas as evidências textuais, a mulher só pode ser "serva" ou, quando muito, "diaconisa", jamais "ministra".

Quanto à relação clero x laicato, independentemente de relações de gênero, no âmbito especificamente masculino, percebe-se, pela análise de 1 Co 3.5, que alguns atores sociais reconhecidos são representados preferencialmente como "ministros", ainda que se mostre que "ministros" também são "servos". De alguma forma, são "servos" diferenciados em relação aos leigos em geral. Paulo e Apolo são exemplos de atores sociais masculinos que são sempre representados de forma positiva no que concerne ao seu status eclesial.

Uma terceira forma de representação ideológica de atores sociais se verifica em conexão com o texto de At 6.2-4, conhecido no meio eclesial posterior como "a instituição do diaconato". Aqui, as premissas dos tradutores os levam a representar, novamente contrariando as evidências textuais, os ministérios social e da palavra como hierarquicamente diferenciados, com prejuízo para o primeiro. Apesar da terminologia do texto original tratar ambos os ministérios de forma equânime, os tradutores qualificam um como "serviço" e outro como "ministério", sugerindo que este é superior àquele.

Uma avaliação global das três versões bíblicas, a partir das passagens analisadas, evidencia que a ARC, caracterizada por uma linguagem mais literal, em função do princípio da tradução por equivalência formal, embora bastante marcada pelas premissas tradicionais dos tradutores, apresenta a vantagem de evitar os acréscimos em relação ao texto original. Esses acréscimos, ao lado da tradução ideologicamente comprometida de termos-chave como os que foram discutidos neste trabalho, funcionam como dispositivos eficazes de veiculação das premissas dos tradutores, como vimos nas versões NVI e NTLH. Aspecto positivo dessas duas versões são progressos

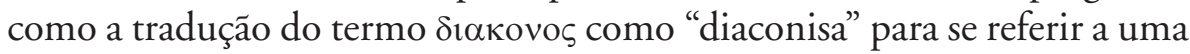


mulher, no caso da NTLH, ou pelo menos a admissão dessa possibilidade de tradução, no caso da NVI.

Enfim, percebe-se que não basta apresentar a Bíblia traduzida numa linguagem contemporânea, orientada pelo princípio da equivalência dinâmica, até porque, em nome da atualização, simplificação e fluência da linguagem, os tradutores se permitem fazer acréscimos ao texto, "complementando" o seu sentido com a veiculação de suas próprias premissas doutrinárias. Observa-se, dessa forma, que mesmo uma atividade técnica, altamente especializada, como é a tradução e, em especial, a tradução de um texto antigo, produzido em línguas não dominadas pela maioria dos usuários da literatura em questão, não se faz sem a utilização de artifícios que, tenham os tradutores consciência disso ou não, contribuem para a manutenção de situações de desigualdade e abuso do poder. Estudos que se dediquem a discutir, esclarecer e denunciar tais artifícios, portanto, se mostram relevantes no desenvolvimento de qualquer perspectiva de estudo que se pretende crítica.

\section{Referências}

BEZERRA, Benedito G. Questôes de gênero em traduções da Bíblia para português e inglês: uma abordagem comparativa. Discurso y Sociedad, v.5, n.3, 2011, 492-513. Disponível em: < http://www.dissoc.org/ediciones/v05n03/DS5\%283\%29Gomes. pdf> Acesso em 25 ago. 2012.

BHATIA, Vijay. Interdiscursivity in critical genre analysis. In: SIMPÓSIO INTERNACIONAL DE ESTUDOS DE GÊNEROS TEXTUAIS, 4, 2007, Tubarão. Anais... Tubarão: UNISUL, 2007. Disponível em:< http://www3.unisul. br/paginas/ensino/pos/linguagem/cd/English/36i.pdf> Acesso em: 25 ago. 2012. BÍBLIA SAGRADA: Almeida Revista e Corrigida. São Paulo: Sociedade Bíblica Brasileira, 1995.

BÍBLIA SAGRADA: Nova Tradução na Linguagem de Hoje. São Paulo: Sociedade Bíblica Brasileira, 2000.

BÍBLIA SAGRADA: Nova Versão Internacional. São Paulo: Sociedade Bíblica Internacional, 2001.

CAMPOS, Giovana Cordeiro. Questôes de tradução, literatura e ideologia. Memento, n.1, v.1, p.56-63, jan.-jun. 2009.

CARMO, Cláudio Márcio. Implicaçōes socioculturais e ideológicas da tradução de textos sensíveis: reflexões a partir do Pai Nosso e suas múltiplas possibilidades de leitura. Linguagem em (Dis)curso, Tubarão, SC, v.11, n.1, p.127-148, jan./abr. 2011. 
FAIRCLOUGH, Norman. Discurso e mudança social. Brasília: Ed. UnB, 2001.

FAIRCLOUGH, Norman. Analysing discourse: textual analysis for social research. London/New York: Routledge, 2003.

GABEL, John B.; WHEELER, Charles B. (Org.). A Bíblia como literatura. São Paulo: Loyola, 1993.

GENTZLER, Edwin. Teorias contemporâneas da tradução. São Paulo: Madras, 2009. GINGRICH, F. Wilbur; DANKER, Frederick W. Léxico do NT Grego-Português. São Paulo: Vida Nova, 1993.

KÜMMEL, Werner G. Introdução ao Novo Testamento. São Paulo: Paulinas, 1982. MARCUSCHI, Luiz Antonio. Da fala para a escrita: atividades de retextualização. 2.ed. São Paulo: Cortez, 2001.

MESCHONIC, Henri. Propositions pour une poétique de la traduction. In : MESCHONIC, Henri. Pour la poétique II. Paris: Gallimard, 1973.

MILTON, John. Tradução: teoria e prática. São Paulo: Martins Fontes, 1998.

MINTON, Roy. Gender-inclusive Bible translations. CTS Journal, n.9, Spring 2003, p.141-146. Disponível em: < http://chafer.nextmeta.com/files/ v9n1_6gender_inclusive_bible.pdf> Acesso em: 25 ago. 2012.

MOITA LOPES, Luiz Paulo. Linguística aplicada e vida contemporânea: problematização dos construtos que têm orientado a pesquisa. In: MOITA LOPES, Luiz Paulo (Org.). Por uma linguistica aplicada indisciplinar. São Paulo: Parábola, 2006. p.85-107.

MORESCHINI, Claudio; NORELLI, Enrico. História da literatura cristã antiga grega e latina I: de Paulo à era constantiniana. São Paulo: Loyola, 1996.

NIDA, Eugene. Toward a science of translation. Leiden: Brill, 1964.

NIDA, Eugene; TABER, Charles R. The theory and practice of translating. Leiden: Brill, 1974.

NOVO TESTAMENTO INTERLINEAR GREGO-PORTUGUÊS. Barueri/SP: Sociedade Bíblica do Brasil, 2004.

OLMI, Olga. A tradução literária: um campo interdisciplinar. Cadernos do CNLF, v.6, n.3, s.p., 2002. Disponível em: <http://www.filologia.org.br/vicnlf/anais/ caderno03-03.html > Acesso em: 28 jun. 2014.

OUSTINOFF, Michaël. Tradução: história, teorias, métodos. São Paulo: Parábola, 2011. RAMALHO, Viviane; RESENDE, Viviane de Melo. Análise de discurso (para a) crítica: o texto como material de pesquisa. São Paulo: Pontes, 2011.

RAMALHO, Viviane; RESENDE, Viviane de Melo. Análise do discurso crítica. São Paulo: Contexto, 2006. 
SOCIEDADE BÍBLICA DO BRASIL. Traduçōes da Bíblia. Disponível em: <http://www.sbb.org.br> Acesso em: 20 ago. 2012.

SOCIEDADE BÍBLICA INTERNACIONAL. Tradução. Disponível em: <http:// www.biblicabrasil.org.br> Acesso em: 20 ago. 2012.

STRAUSS, Mark L. Current issues in the gender-language debate: a response to Vern Poythress and Wayne Grudem. In: SCORGIE, Glen G.; STRAUSS, Mark L.; VOTH, Steven M. (Ed.). The challenge of Bible translation: communicating God's Word to the world. Grand Rapids: Zondervan. 2003. p.1-31. Disponível em: $<$ http://reclaimingthemind.org/papers/ets/2006/Strauss_Mark/Strauss_Mark. pdf> Acesso em 23 ago. 2012.

THE ANALYTICAL GREEK LEXICON. New York: Harper \& Brothers/London: Samuel Bagster \& Sons, s.d.

VAN DIJK, Teun A. Discurso e poder. São Paulo: Contexto, 2008.

Data de submissão: 02/05/2014. Data de aprovação: 29/09/2014. 
